Int. J. Electrochem. Sci., 14 (2019) $6814-6825$

International Journal of

ELECTROCHEMICAL

SCIENCE

WWW.electrochemsci.org

\title{
Electrochemical Studies of Bitter Gourd (Momordica charantia) fruits as Ecofriendly Corrosion Inhibitor for Mild Steel in 1 M HCl Solution
}

\author{
Aijuan Zhao ${ }^{1}$, Haijie Sun ${ }^{1, *}$, Lingxia Chen ${ }^{1}$, Yufang Huang ${ }^{1}$, Xingjie Lu ${ }^{2, *}$, Bing Mu ${ }^{1}$, \\ Hairong Gao ${ }^{1}$, Shaoqing Wang ${ }^{l}$, Ambrish Singh ${ }^{3}$ \\ ${ }^{1}$ Institute of Environmental and Catalytic Engineering, College of Chemistry and Chemical \\ Engineering, Zhengzhou Normal University, Zhengzhou 450044, Henan, China. \\ ${ }^{2}$ Henan Institute of Metrology, Zhengzhou-450000, Henan, China. \\ ${ }^{3}$ School of Materials Science and Engineering, Southwest Petroleum University, Chengdu, Sichuan \\ 610500, China. \\ *E-mail: sunhaijie406@zznu.edu.cn, xingjieluzznu@163.com
}

doi: $10.20964 / 2019.07 .75$

Received: 9 March 2019 / Accepted: 22 April 2019 / Published: 10 June 2019

Fruits extract of Momordica charantia (MCFE) was characterized using gas chromatography (GC), and mass spectrometry (MS) methods. The influence of MCFE on corrosion of mild steel in $1 \mathrm{M} \mathrm{HCl}$ solution was evaluated using static electrochemical methods. Electrochemical Impedance Spectroscopy (EIS) and polarization studies were performed to derive the kinetic mechanism taking place at the electrodes. Micro-electrochemical tests were performed using scanning electrochemical microscopy (SECM) technique. The surface was further examined by scanning electron microscope (SEM). The EIS results suggested that the increase in the concentration of MCFE increased the inhibition efficiency. Polarization statistics pointed towards the changes in the anodic and cathodic kinetics, but overall shift of $-E_{\text {corr }}$ was less than $85 \mathrm{mV}$ suggesting the MCFE inhibitor belongs to mixed type category. SEM studies revealed that the surface of the mild steel was quite unaffected with MCFE film on it in $1 \mathrm{M} \mathrm{HCl}$ solution.

Keywords: Mild steel; Momordica charantia; Corrosion; EIS; SECM; GC-MS

\section{FULL TEXT}

(C) 2019 The Authors. Published by ESG (www.electrochemsci.org). This article is an open access article distributed under the terms and conditions of the Creative Commons Attribution license (http://creativecommons.org/licenses/by/4.0/). 